\title{
LOS ZOQUES DE TUXTLA Y LA DISPUTA POR LAS VIRGENCITAS DE COPOYA, EN EL VALLE CENTRAL DE CHIAPAS
}

\section{THE ZOQUEZ OF TUXTLA AND THE DISPUTE FOR LITTLE VIRGINS OF COPOYA, IN THE CENTRAL VALLEY OF CHIAPAS}

\author{
Jorge Luis Cruz-Burguete $^{1}$ y Patricia Elizabeth Almazan-Esquivel ${ }^{2}$
}

${ }^{1}$ Investigador titular de El Colegio de la Frontera Sur, miembro del SNI y Estudia identidades colectivas, migración interna e internacional y cambio social. ${ }^{2}$ Maestra en Ciencias de la Educación por el Colegio de la Frontera Sur.

\section{RESUMEN}

Tuxtla Gutiérrez, capital del actual estado de Chiapas, tuvo su origen en un caserío zoque denominado Coyatocmó. Posteriormente, con la presencia de los nahuas pasó a denominarse Tuxtlán (de Tochtlic, conejo, y Tla, lugar o abundancia). Sus vecinos chiapanecas le conocían como Nacúa (de Ni-hú, conejo); y los tzotziles como Tulún (de t'ul, conejo, y lum, tierra). Es decir, en cualquier lengua, el área de los zoques fundadores de Tuxtla se conoce como casa, lugar o tierra de conejos, simbolizándose en un jeroglífico nahua que representa un conejo sentado sobre tres granos de maíz (Tovar, 1988; Morales, 1980). Por su parte, Copoya significa "lugar de luna llena" o "donde brilla la luna". Se localiza en el límite Suroriental del territorio zoque, en las orillas del sur de Tuxtla, es un poblado de origen prehispánico con una población actual de 4, 500 habitantes. A finales del año 2003 se nombra el primer sacerdote católico, pues los "copoyeros" no habían aceptado el dominio religioso de Tuxtla desde su fundación por los mercedarios en 1536; o los dominicos en 1539 y los franciscanos entre 1540 y 1541 (Carvalho, 1994:139). Con el nombramiento del sacerdote, se divide la población entre "encuentristas" de Copoya y "tradicionalistas zoques" de Tuxtla, y ha iniciado la disputa por la posesión de las virgencitas. En marzo de 2004 se produce el primer enfrentamiento, y en abril la violencia se apodera de ambos sectores. Actualmente ambos grupos afirman que las cosas están en calma, pero la feligresía es cooptada en abundancia y crecen separadamente. Se ha perdido el lucimiento con que se unía la pequeña comunidad zoque de Copoya a la gran capital Tuxtleca, y han pasado a una fase más popular y renovadamente religiosa. Pero...¿podrán borrarse cientos de años de fiestas religiosas en que las virgencitas subían a Copoya y bajaban a Tuxtla Gutiérrez?

Palabras clave: Zoque de Tuxtla, Virgen, Capoya.

\section{SUMMARY}

Tuxtla Gutierrez, capital city of Chiapas, has its origins in a zoque household named Coyatocmó. Lately, with the presence of nahuas become Tuxtlán (from the word Tochtlic, rabbit, and Tla, place of abundance). It's neighbors from Chiapas knew it as Nacúa (from the word Ni-hú, rabbit); and the tzoltziles like Tulún (from the word t'ul, rabbit, and lum, land). That is, in every language, the zoque's area founders of Tuxtla it's known as home, place or land of rabbits, simbolizing in a nahua hieroglyph that shows a rabbit sit down on three maize seeds (Tovar, 1988; Morales, 1980). In the other hand, Copoya means "place of full moon" or "where moon shines". Its located in the limit between southeast of zoque territory, in the shores of the south of Tuxtla, it's a village from prehispanic origins with a current population of 4,500 persons. At the end of 2003 was named the first catholic preast, because the copoyeros haven't accepted the religious domain of Tuxtla since it's foundation by mercenaries in 1536; or the Dominicans in 1539 and the franciscanes between 1540 and 1541 (Carvalho, 1994: 139). With the named of the preast, was divide in "encuentristas" of Copoya and "tradicionalistas zoques" from Tuxtla, and a dispute has begin for the possession of the little virgins. In march of 2004 start the first confrontation, and in april the violence seizes both sectors. Currently both groups say that the things are calm, but the parishes develop separated. Has been loss the bond that join the little zoque community of Copoya in the great capitol Tuxtleca, and has been passed to a next phase more popular and renewed religious. But... ¿Could the hundreds of years been erased of religious holidays in which the little virgins raise to Copoya and get down to Tuxtla Gutierrez?

Key words: Zoquez from Tuxtla, little virgins of Copoya. 


\section{Los zoques de Coyatocmó, Tuchtlán o San Marcos evangelista Tuxtla}

Tuxtla Gutiérrez es la capital de Chiapas y se ubica en territorio zoque. Las principales poblaciones zoques en la depresión central de Chiapas eran Mezcalapa, Quechula, Tecpatán y Copainalá; en los límites con el Istmo de Tehuantepec se situaban en los Chimalapas y Tapanatepec; y en el margen oeste del Grijalva se asentaban las poblaciones en Tuxtla, el valle de los Corzos, Ocozocuautla, Cintalapa y Jiquipilas, aunque también habían asentamientos en el Soconusco y la costa del Pacífico.

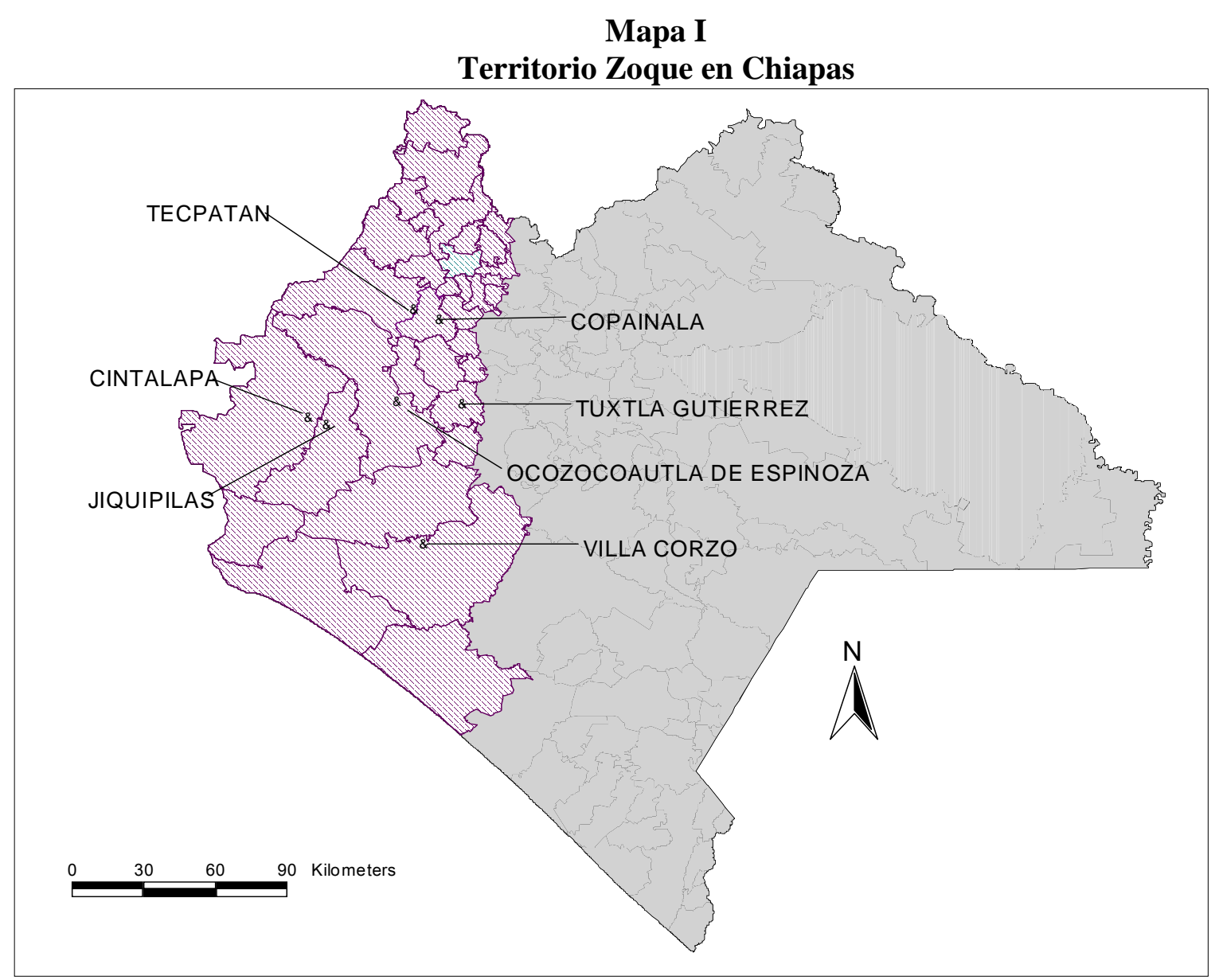

Elaboró: Tec. Juan Sántiz Girón, Ecosur, con datos de INEGI, 2000.

Los zoques forman una amplia familia lingüística, junto con mixes (en Oaxaca) y popolucas (en Veracruz) están asociados "con la primera civilización urbana que floreció en la costa del Golfo desde hace tres mil años: la cultura olmeca o de La Venta" (García de León, 1985: 29). 
Los zoques cultivan maíz, frijol, calabaza, tomate, jícara (del palo de morro), chile, cacao y algodón, y completan su alimentación con una gran variedad de yerbas y animales de caza. En el pasado recolectaban grana cochinilla de los nopales, una sustancia para teñir los tejidos con tinturas naturales (creando diversas tonalidades del rojo); también recogían en la víspera del tiempo de lluvias una hormiga gigante (denominada chicatana o nucú) para consumirla asada, y recogían caracol (o schuti) en los arroyos, con el que aún se elabora un exquisito platillo, tan rico en nutrientes como en sabores. ${ }^{1}$

Los pueblos de Tuxtla, Osumacinta, Chicoasén, Jiquipilas, Coapilla y Ocozocuautla se volvieron tributarios de los chiapanecas, los cuales lograron construir uno de los señoríos militares más poderosos antes de la conquista española, que no pudo ser dominado por los aztecas jamás (García de León, 1985).

En cambio, los nahuas dominaron a los zoques hacia 1482 convirtiéndolos en tributarios de maíz, incluídas la Fraylesca y el Soconusco (Tovar, 1988). Aunque respetaron la estructura organizativa de los zoques, y evitaron imposiciones políticas, las presiones de los nahuas terminaron por dominar las rutas comerciales y reducirlos, imponiendo topónimos a cada lugar, cerro, montaña, río, laguna, hondonada, rivera, ojo de agua, cueva o paraje, los cuales serían re-bautizados con apelativos de algunos santos a la llegada de los españoles (Villasana, 1995:29).

Cuando llegaron los chiapanecas, se incrustaron como una ajustada cuña entre zoques y tzotziles, y formaron asentamientos en la rivera Oriente del Río Grande, extendieron su señorío hacia el Grijalva Medio, fundando las poblaciones de Chiapa, Acala, Ostuta, Pochutla y Suchiapa; y más hacia el Sur promoviendo el florecimiento del valle de Cutilinoco, que daría lugar a la Fraylesca (García de León, 1985).

\footnotetext{
${ }^{1}$ La tendencia a su desaparición es evidente --aunque no inminente--, ya sea porque las nuevas generaciones no degustan estos sabores, o porque simplemente no lo conocen. En Copainalá y Tecpatán aún hay la costumbre y el orgullo por los caracoles "gigantes". Igualmente, se acostumbra recolectarlos en el río Nandaburé (cerca de Acala) y en los ríos cercanos a Ocosingo (en Toniná). También, aunque un poco más difícil, se puede solicitar este suculento platillo en algunos restaurantes y bares de Tuxtla Gutiérrez.
} 
Mapa 2

Las regiones socioeconómicas de Chiapas

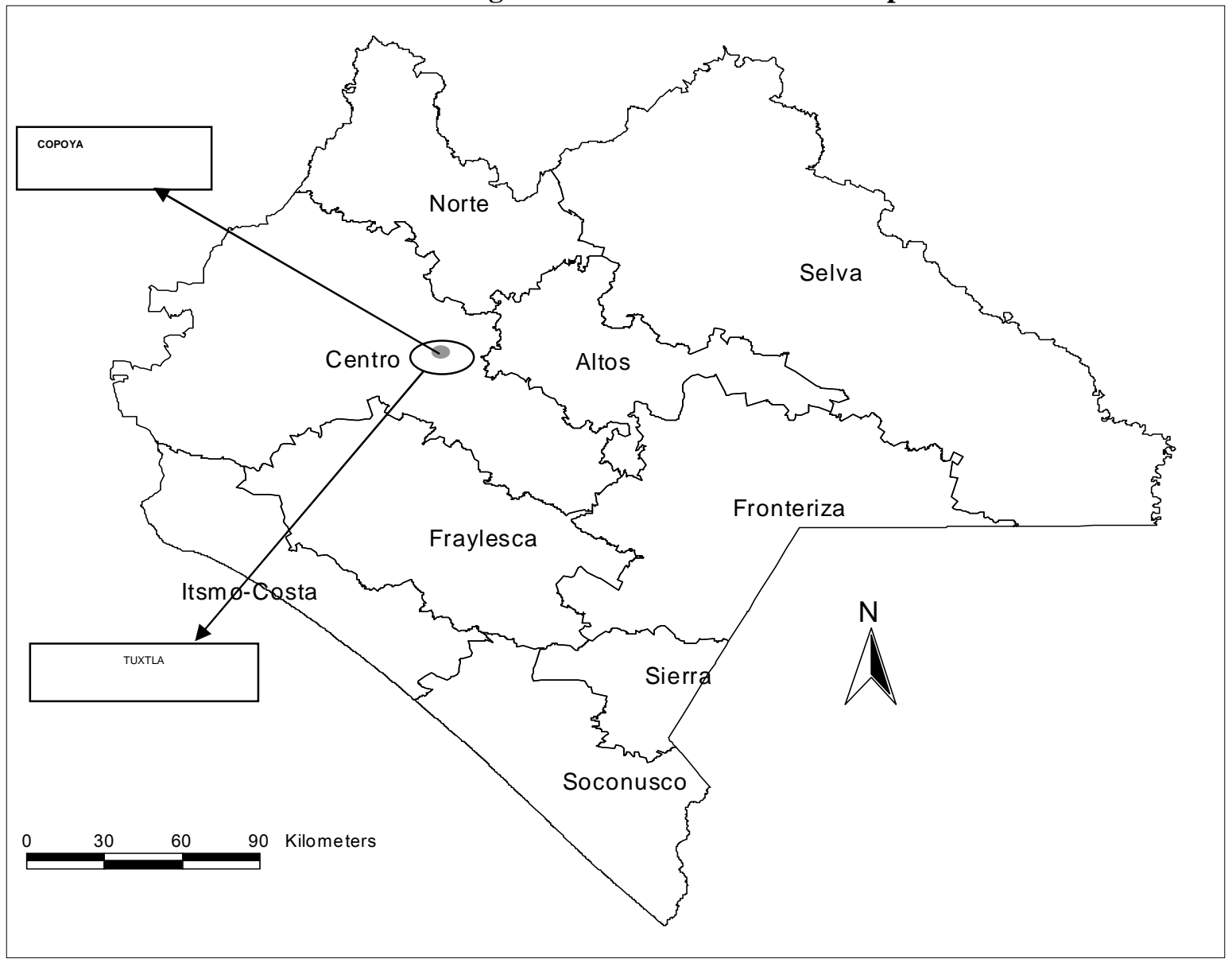

Elaboró: Tec. Juan Sántiz Girón, Ecosur, con datos de INEGI, 2000.

\section{El origen}

Se estima que a mediados del siglo VI A.C., en la depresión central de lo que hoy es el estado de Chiapas, se asentó uno de los señoríos zoques que a la postre daría lugar al nacimiento de Coyatocmó, luego Tuchtlán y finalmente San Marcos Evangelista Tuxtla. Más de 21 arroyuelos se unían a los cauces principales de Quishimbac o río Sabinal, el Potinaspak y San Roque, hasta desembocar en la cuenca principal del ahora denominado río Grijalva. $^{2}$ De ese crucero fluvial partieron los zoques fundadores hacia el centro de la

\footnotetext{
${ }^{2}$ En la carta urbana de la ciudad de Tuxtla Gutiérrez (2001) todavía se registra la red fluvial de la ciudad, llegándose a contar 10 afluentes del lado norte y 11 de la zona sur, que desembocan en el río El Sabinal, el cual a su vez va creciendo hasta desembocar en el río Grijalva.
} 
actual Tuxtla Gutiérrez, asentándose bajo una gigantesca ceiba o "pochota" y formando el señorío de Coyactocmó (Tovar, 1988).

Con la presencia más constante de los nahuas entre los zoques, entre 1482 y 1505, el caserío que dio origen a Coyactocmó, pasó a denominarse Tuxtlán (de Tochtlic, conejo, y Tla, lugar o abundancia); pero también entre los chiapanecas se les conocía como Nacúa (de Ni-hú, conejo); y entre los tzotziles como Tulún (de t'ul, conejo, y lum, tierra). Es decir, en cualquiera de las lenguas, el área de los zoques fundadores de Tuxtla se conoce como casa, lugar o tierra de conejos, simbolizándose en un jeroglífico nahua que representa un conejo sentado sobre tres granos de maíz (Tovar, 1988; Morales, 1980).

\section{Tuxtla en la Colonia}

La Iglesia jugaría el más importante papel en el establecimiento y preservación del orden colonial en toda la región centroamericana. A través de las órdenes monásticas, la Corona española asumió la tarea de evangelizar a los naturales, por lo que arribaron a territorio chiapaneco los mercedarios en 1536, luego los dominicos en 1539 y los franciscanos entre 1540 y 1541 (Carvalho, 1994: 139).

Los dominicos fundaron en 1550 la Villa de San Marcos Evangelista Tuchtla, pretendiendo con ello congregar a los indios dispersos y convertirlos al cristianismo, controlar el satanismo y procurar la aniquilación de las "idolatrías" de los indios, además de la recaudación de los tributos. La presencia de los frailes dominicos, así como las acciones de "juntar y reducir" a la población, vienen a ser las primicias del cambio tanto de la organización social como del territorio:

Con la conquista, el asentamiento prehispánico sufrió un cambio significativo al transformar la aldea de chozas dispersas a otro tipo de organización espacial más geométrico y ordenado, debido a que los conquistadores y evangelizadores impusieron un patrón de asentamiento que convenía más a sus intereses de dominio y control, poniendo alto a las religiones, estructuras sociales y económicas prehispánicas, situación que no fue privativa de Tuxtla sino de todo el continente latinoamericano (Mérida, 2000:12). 
Al fundarse San Marcos Evangelista Tuchtla se fortaleció la estructura colonial y con ella la Iglesia Católica y el cristianismo en la región, pues fue a partir de las parroquias, las capillas y los atrios de las iglesias y conventos como se organizaron los barrios al definirse el espacio urbano, además de regir, desde las cofradías, las actividades de la vida cotidiana, las relaciones del vecindario, el comercio y las fiestas de los santos patrones de los pueblos. Su población fue en aumento hasta alcanzar 900 habitantes en 1611, y 3775 en 1650. Sin embargo, al igual que el resto de la región centroamericana la población indígena sufrió una drástica caída a fines del siglo XVII, como resultado de la confluencia de diversos factores, entre ellos los trabajos forzados y las epidemias. Por ello, a finales del siglo XVII la población de San Marcos se redujo a 1500 habitantes (Tovar, 1988:8).

Durante el siglo XVIII los informes de los curas reportan un crecimiento de la población que alcanzó los 3000 habitantes entre 1736 y 1750. En 1764 se creó la alcaldía de Tuxtla, oficialmente denominada San Marcos Tuxtla, con jurisdicción sobre los zoques y chiapanecas. Su ubicación, entre los dos principales asentamientos de la época, la convirtieron en ruta de paso para el intercambio mercantil de la época. Con el aumento de asentamientos zoques y de grupos mestizos, para 1775 la población había ascendido a 3580 pobladores entre los que se contaban indios zoques (quienes representaban un poco más de la mitad de la población), negros y mulatos, mestizos y blancos.

En 1813 el pueblo de San Marcos Tuxtla fue elevado a la categoría de villa, creándose aquí una diputación provincial que atendía los asuntos de Chiapas, y en 1822 el ayuntamiento de Villa de Tuxtla juró reconocimiento al imperio de México gobernado por Agustín de Iturbide.

El siglo XIX fue testigo del crecimiento y consolidación de un grupo de tendencia liberal en la Villa de Tuxtla que desafiaría al poder de San Cristóbal que hasta entonces se mantenía como el centro de poder económico, político y social de Chiapas. Esta rivalidad afloró en 1822 a la que seguirían una serie de enfrentamientos entre los grupos de poder de ambas ciudades cuando en 1833 Tuxtla se convirtió en capital del estado por primera vez. En 1848 la ciudad de Tuxtla fue designada con el nombre de Tuxtla Gutiérrez en honor a 
Joaquín Miguel Gutiérrez, líder local que combatió la facción san cristobalense, a cuyas manos murió.

En 1892, año en que la ciudad se constituye en capital del estado, la ciudad empieza a experimentar algunos cambios en la estructuración de su espacio, de manera que su constitución predominantemente rural pasa a convertirse en una ciudad que se desarrolla como capital comercial y de prestación de servicios públicos. Algunos estudiosos del desarrollo urbano de Tuxtla Gutiérrez, (Noguez, 1997; Malo, 1997; Mérida, 2000) ubican como el primer momento de su crecimiento demográfico a partir del año en que se establece como capital del estado, hasta 1940.

El segundo momento del crecimiento urbano se ubica en el periodo que va de los años cuarenta a los setenta. Es en 1940 que el gobernador Rafael Pascacio Gamboa (1940-1944) orienta las acciones públicas y privadas para construir la infraestructura y equipamiento urbano que posibilitaran la consolidación de la ciudad de Tuxtla Gutiérrez como la capital del estado de Chiapas.

Entre las obras de este periodo destaca la construcción de la Carretera Panamericana, que significó un acontecimiento importante para la ciudad, “....convirtiéndose en poco tiempo en el detonador del crecimiento alrededor del cual giraría su política, su comercio y su economía" (Noguez, 1997:44). Con esta obra la ciudad se desarrolla siguiendo el trazo de la carretera, principalmente hacia el lado poniente, que se empieza a consolidar como la zona de mayor desarrollo económico y de equipamiento urbano.

En este periodo también destaca la construcción del mercado público "Rafael Pascacio Gamboa”, que permite la concentración de la actividad comercial al lado sur de la Plaza Central, principalmente sobre la actual $1^{a}$ calle poniente, como parte de la consolidación de la "ciudad interior" de Tuxtla Gutiérrez (Escobar, 1997:76) . ${ }^{3}$

\footnotetext{
${ }^{3}$ De acuerdo a Escobar, la ciudad interior "está constituida por aquellas partes del área urbana en la que se llevan a cabo las llamadas funciones centrales de la ciudad, es decir, aquellas actividades relacionadas con la dominación política e ideológica, la administración pública y privada, la gestión institucional, el comercio especializado, los servicios financieros, las actividades concentradoras de empleo, los servicios a la producción, el consumo especializado, y las representaciones culturales de la vida social" (Escobar, 1997: 68)
} 


\section{La oferta religiosa en Chiapas}

De los estados sureños Chiapas es el más fronterizo de la república mexicana; tiene una superficie que abarca el 3.8\% del territorio nacional (el $8^{\circ}$. lugar en extensión territorial); cuenta con 118 municipios distribuidos en 9 regiones socioeconómicas. Colinda al norte con Tabasco; al este 20 de sus municipios limitan con Guatemala, con una extensión que significa el 58\% de la frontera sur mexicana; al sur con el Océano Pacífico, y al oeste con Oaxaca y Veracruz.

Chiapas conforma un accidentado territorio que comprende desde las llanuras costeras del Pacífico hasta las montañas de oriente, pasando por la Depresión y el Altiplano central. Es bañado por una abundante red fluvial alimentada por más de 50 ríos en la vertiente del Golfo y 74 afluentes en la vertiente del Pacífico, además de lagos, lagunas y embalses que equivalen al 30\% de la red hidrológica del país. Por si ello fuera poco, el $30 \%$ de la precipitación pluvial nacional se concentra en los estados de Tabasco y Chiapas, en éste último la precipitación anual alcanza los 3000 milímetros (Cruz, 1998; Agenda Estadística de Chiapas, 2000).

Según el INEGI, en el 2000 la población era de 3,920,892 habitantes, con una toma de $2.03 \%$. De ellos el $24.62 \%$ de 5 años y más es hablante de lenguas indígenas, proporción sólo superada por los estados de Yucatán y Oaxaca. El 37.40\% de la población ocupada recibe menos de un salario mínimo y $20.10 \%$ de uno a dos, es decir, el $57.50 \%$ se encuentra en niveles de pobreza extrema. El $66.02 \%$ de la población masculina económicamente activa trabaja en el sector primario y el $54.5 \%$ de la población femenina en el sector terciario, en actividades relacionadas con el comercio, transporte, gobierno y otros servicios (Agenda Estadística de Chiapas, 2000).

En materia religiosa, Chiapas ha vivido fuertes cambios hacia diversos protestantismos a partir de las últimas tres décadas del siglo pasado. En estos años se empieza a producir un notable decremento del catolicismo: 1970 (91.2\%); 1980 (76.9\%); 1990 (67.6\%) у 2000 
(63.8\%), en tanto que los religiosos no católicos se incrementaron hasta llegar en el 2000 a un 36.14\% (INEGI, en Rivera, 2004:39).

Hasta los años sesenta en Chiapas no existían templos protestantes oficialmente reconocidos. ${ }^{4}$ En Tuxtla, toda relación con el protestantismo estaba referida a Guatemala o al centro del país. Probablemente los que vivieron el "programa bracero" y viajaron a Estados Unidos a mediados del siglo XX, o quienes habían estado por algún tiempo en el centro o norte de México, pudieron incursionar en el cambio religioso. Pero las zonas indígenas en Chiapas eran consideradas esencialmente territorio católico, hasta que se demostró lo contrario a mediados de los años setenta.

Si tomamos en cuenta que la estructura del sistema de cargos en las comunidades indígenas integra actividades económicas, agrícolas, religiosas, educativas y de salud, englobadas en la producción y usufructo de los bienes culturales, que organizan la comunidad, podemos entender que las fiestas religiosas se acoplan a los ciclos agrícolas, a la organización social y a la división del trabajo, atendiendo al género y la generación.

También hay que señalar que la estructura de poder en las comunidades tradicionales está compuesta por dirigentes con cargos de representación hacia el exterior, pero a la vez éstos mismos son funcionarios públicos en el ejido o la agencia municipal, además de ser líderes en la organización de las fiestas religiosas. Es decir, se trata de una estructura armónicamente funcional para articular la religiosidad indígena tradicional, la comunidad agraria y la instancia política, jerárquicamente organizadas por los consejos de ancianos, funcionarios públicos y líderes religiosos, es decir: "los principales".

A mediados de los años setenta aparecen los conflictos religiosos en la región Altos de Chiapas, y aunque después se supo que también en la Selva y la región Norte de la entidad hubieron indicios de intolerancia religiosa, San Juan Chamula significó el prototipo de los "expulsados por motivos religiosos".

\footnotetext{
4 Carolina Rivera afirma: “...las primeras experiencias con protestates históricos (presbiterianos principalmente) se vivieron desde finales del siglo XIX en municipios chiapanecos situados en la frontera con Guatemala (Rivera, 2004: 23)"
} 
[...] Chamula siempre destacó por la continuidad de esta práctica a lo largo de varias décadas. Siendo el municipio más densamente poblado del altiplano, Chamula se convertiría en el primer expulsor de población que se establecería en la ciudad de San Cristóbal de las Casas, y áreas adyacentes, principalmente en el vecino municipio de Teopisca (Robledo, 2004).

Se trataba de expulsiones en situación de violencia, en las que familias enteras tenían que abandonar sus casas ante las amenazas de ser incendiadas con las personas dentro. El motivo fundamental era la conversión de familias al evangelismo protestante y su consecuente negación a seguir participando en las fiestas tradicionales del pueblo. Esto implicaba negarse a cooperar ya fuera en trabajo o dinero para las festividades católicas, así como abandonar el consumo de alcohol, el baile y demás actividades consideradas "mundanas". En suma, se enfrentaba una tradición basada en el sistema de cargos, con una estructura caciquil muy rígida, y ampliamente soportada por una base social que por centurias había aceptado sin cuestionar todo el poder que se ejercía desde "la costumbre".

Tomar trago para alegrar el "chulel" (es decir, el alma), bailar y quemar candela y copal en las iglesias, así como quemar cuetes, bombas y cámaras, en medio de la algarabía popular durante las ventas de frutas y comidas tradicionales en atrios y parques, más el constante bullicio de la flauta y el tambor, el arpa o la guitarra, eran actividades que "los evangélicos" empezaron a rechazar, lo cual molestaba a las autoridades tradicionales y el resto del pueblo. Después vendrían las presiones para disuadir a los "evangélicos" de su apatía por "la costumbre", luego se incrementaron los conflictos intrafamiliares ligados a partidos políticos y grupos protestantes, hasta el enfrentamiento con la autoridad, quienes tomaban el acuerdo en nombre de "la comunidad" para sacarlos por las buenas o por las malas. Los resultados fueron, regularmente, algunas casas quemadas y las expulsiones violentas.

Sin embargo, lejos de haber sido un fenómeno coyuntural y regional, el conflicto entre los grupos "tradicionalistas" y los "evangélicos" se ha exacerbado en tanto crecen los grupos protestantes. Estos se informan de sus derechos civiles y religiosos como mexicanos, y se radicalizan para mantenerse en sus comunidades de origen o negociar su salida. El fenómeno se extendió a distintas regiones y grupos étnicos en toda la geografía chiapaneca: 
de Los Altos a las Selvas (Lacandona y Chimalapas), de la Sierra a la zona Norte, y del Centro hasta la Costa y el Soconusco, con múltiples relaciones y demandas que pasan del campo religioso a lo étnico, social, cultural, político y económico.

Las rupturas comunitarias provocadas por el cambio religioso hacia el evangelio protestante son un grave conflicto en todo Chiapas, y siempre se asocia con su proximidad a la violencia. Por si fuera poco, a las relaciones del poder religioso en disputa hay que agregar el ingrediente de las nuevas prácticas neocatólicas a partir de la teología de la liberación, pues la recomposición católica, en su afán por enfrentar la disidencia religiosa, ha incorporado a su ritualidad prácticas cercanas a los pentecostés, tales como: 1) brindar un espacio de participación a las mujeres, los niños, jóvenes y ancianos; 2) incrementar la autoestima de los pobres comparándolos con "el rostro del Cristo ensangrentado"; 3) disuadir a los varones del consumo de alcohol y criticar fuertemente el maltrato a mujeres y niños, entre otras. Además, ha creado un espacio en su estructura para la participación de diáconos y catequistas que replican constantemente el nuevo discurso de la Teología de la Liberación.

Dentro de la Iglesia Católica también ha tenido cabida otra rama del catolicismo tradicional, más agresivo y con una posición autoritaria, pero con prácticas renovadas para los retiros espirituales, denominados "encuentros con cristo". Se trata de reunir a conjuntos de personas desde la tarde del jueves hasta la tarde del domingo en recintos contiguos a la Iglesia, primero inician con jovencitas, luego con jovencitos (por separado y con espacios de un mes entre uno y otro encuentro), después mujeres adultas y luego hombres adultos y, finalmente, los encuentros con parejas. Estos no replican el discurso de la nueva Teología de la Liberación, pero sí han integrado a asus actividades las lecturas de la Biblia, otorgan la palabra en público, durante las misas, a las mujeres y hombres que quieran dar sus testimonios, y participan activamente en otras actividades con la Iglesia.

Junto a los diversos protestantismos, el neocatolicismo "pentecostalizado" ha reformando la feligresía chiapaneca. Los cambios trascienden comunidades, regiones, entidades y naciones. Son fuerzas en el campo religioso que se disputan el ejercicio del poder sobre las 
conciencias; por su parte, los actores religiosos también se encuentran muy activos, organizados e informados, pero también próximos a la violencia. ${ }^{5}$

Después del levantamiento zapatista el gobierno prestó atención al fenómeno religioso, especialmente en Los Altos, pero la intolerancia religiosa ya había cobrado fuerza en varios puntos del territorio chiapaneco. La llegada masiva de las familias de la zona de conflicto a San Cristóbal trajo consigo asentamientos irregulares y el surgimiento de infinidad de templos "evangélicos". Otro tanto ocurrió en Las margaritas, Ocosingo, Altamirano, Comitán y Yajalón, entre los más importantes. Así, los conceptos "evangélicos", "expulsados" y hermanos indígenas pobres, se asoció directamente con las invasiones de predios urbanos, la indianización de las ciudades y los problemas de hacinamiento e insuficiencia de servicios.

En un principio se pensó que el conflicto religioso era localizado, y sólo en San Juan Chamula se daban las "expulsiones religiosas". Luego supimos que se repetía en varias comunidades de Los Altos de Chiapas, el Norte y la Selva, pero en todos los casos el gobierno consideró que era un asunto de indígenas, de las diferencias culturales y la incomprensión de la lengua oficial o la pobreza. Lo que menos imaginaron los habitantes de Tuxtla Gutiérrez fue que esos problemas estarían en la capital de Chiapas, y menos aún que el conflicto incluiría a las "virgencitas de Copoya", el último reducto de las fiestas tradicionales de los zoques.

\section{La disputa por las vírgenes}

Tuxtla Gutiérrez es la capital y la más importante ciudad de Chiapas. Según el Censo del 2000 el municipio tenía 434, 147 hab. Sólo la ciudad contaba con 424, 579, es decir el

\footnotetext{
${ }^{5}$ Una nota reciente señala "Fidelino Lorenzo Hernández, indígena tzeltal del ejido 'Nuevo Poblado Las Tacitas' fue privado de su libertad y a sus hijos se les prohíbe recibir clases en la escuela de ese lugar por el simple hecho de profesar una religión diferente a la católica (Surge la intolerancia religiosa en la Selva, Cuarto Poder, pág. B18, 4 de diciembre de 2004.
} 
97.79\%, y el resto se distribuye en 83 pequeñas localidades. ${ }^{6}$ La comunidad del ejido Copoya es la más grande y depende de este municipio, tiene 4,877 habitantes, y es el único pueblo que -estando junto a la capital de Chiapas - aún conserva su organización ejidal y su estructura económica y sociocultural gira en torno a sus tres virgencitas: 1) Candelaria, 2) Asunción y 3) Santa Teresita de Olachea, es decir, dentro del gran territorio zoque en los valles centrales de Chiapas, es un oasis sociocultural, étnico y religioso. A decir de Amalia (CO63) la deidad más importante es la "virgen santísima", y aunque se hable en singular, se refiere a las tres virgencitas: ${ }^{7}$

Tenemos que venir también pue' porque es nuestra madre santísima. Ella es la patrona de Copoya, sí, ella es la patrona de Copoya, porque ahí le hicieron su Iglesia, porque ahí lo quería, porque ahí me decía pue' mi papá que ya no... ella ya no se movía de allí [...], lo llevaban pues pa' allá para San Vicente, y de allá, dicen, pue' que aquí apareció. Es que era aparecida, pues, donde quiere su Iglesia ahí se queda (trabajo de campo, 2005).

El significado de Copoya puede ser "lugar de luna llena" o "donde brilla la luna". Atendiendo a su situación orográfica, destaca su ubicación en una meseta con una extensión de 30 kilómetros de largo por 10 kms de ancho aproximadamente, desde donde se observa la capital chiapaneca a escasos seis kilómetros, y con una altitud de 80 a 90 metros por encima del valle de Tuxtla Gutiérrez. Se localiza en el límite Suroriental del territorio zoque (el cual se extiende en los Valles Centrales de Chiapas, el Oriente de Oaxaca y el Sur de Veracruz), y es un poblado de origen prehispánico donde se construyó la primera ermita católica, para impedir que los indígenas siguieran con sus "idolatrías".

Otra definición de Copoya puede ser "copo" (alto) y "yapán” (el que manda, con poder), que se interpretaría como "el poder más alto", o "el patrón mayor", atendiendo a sus raíces zoques.

\footnotetext{
${ }^{3}$ Con el crecimiento de Tuxtla Gutiérrez se hace más notoria la marginalidad de la población en la periferia de la ciudad, la pobreza, la baja escolaridad, la anarquía, el incremento del consumo de alcohol y las drogas entre la juventud, y la migración predominantemente centroamericana.

${ }^{7}$ De aquí en adelante aparecen testimonios, los cuales son vertidos por los lugareños, y para proteger su identidad utilizo seudónimos con un nombre propio más datos del lugar donde se levantó la información y la edad del informante, por ejemplo Amalia (CO63), pero no pondremos apellidos. Sin embargo es importante señalar que existen apellidos de origen zoque, o una mezcla de zoque-chiapaneco, como: Cundapí, Chandoquí, Jonapá, Nangusé, Nanguyasmú, Consospó, entre otros, que se combinan con apellidos como Gutiérrez, Pozo, Velásquez, Tevera, Morales, etc.
} 
De cualquier manera, la mesa de Copoya y el gran cerro de Mactumactzá -que remata la meseta en el oriente- han sido considerados como "lugares de culto" o "Los refugios de lo sagrado", como titula su libro Dolores Aramoni (1992). Principalmente si se atiende a la vastedad de cuevas, consideradas como "encantadas", que sólo en su cara al Norte tienen una extensión de poco más de 1000 metros, según los espeléologos, y eso que aún hace falta investigar su cara Poniente y Sur (Nuevas exploraciones en la meseta de Copoya, Vaxakmen, 2004).

Pese a todo, Copoya siempre estuvo al márgen de la estructura Católica, practicando una religiosidad popular construida con mixturas de imágenes sagradas y respetando los sacramentos, pero predominando las formas de organización social, la cosmogonía y la cultura zoque, sin atender el dominio político y religioso de Tuxtla Gutiérrez, desde su fundación por los mercedarios en 1536, pasando por los dominicos en 1539 y los franciscanos entre 1540 y 1541 (Carvalho, 1994:139). Como indica don Ricardo (TX70):

Pues fíjese usted que yo se muchas cosas [...] yo tengo un mi bisabuelo, ya se murió, se llamaba Reynaldo González Velásquez [...] él se vestía como indito, anteriores, puro blanco, camisa pantalón blanco [...] yo ya empecé a andar con la virgen cuando mi abuelito me llevó, pero yo estaba chico todavía [...En] la Iglesia Grande de San Marcos se adornaba la santísima cruz, pero como ahora ya cambió el tiempo, el cura...., no sé, ya no se hace eso, porque había una santísima cruz que se adornaba, lo que usted quisiera: flores, flores de putzá o lo que llevara la gente, lo pasaban a los santos para bendecidlos y lo traían a su casa. Este señor obispo lo ha querido cambiar ¿no?, porque la virgencita siempre llegaba a la Iglesia de San Marcos ¿no?, bendecían y todo. Ahora ya no, ahora pertenecen a San Pascualito $[\ldots]$ y nos dijo que cuando nosotros queramos, que la virgen esté dos o tres días en su casa, en la Iglesia ¿verdad? [...] como dice él "miren aunque sea frijolitos pero yo les doy de comer", pero señor, nosotros no llegamos por al comida, nosotros llegamos por la madre santísima ¿no? ya venimos desayunados y todo, ya si nos invitan un pozolito ¡que bueno; (trabajo de campo, 2005).

Sin embargo, pareciera que los evangelizadores tuvieron la habilidad de encontrar algunas semejanzas entre los ritos mesoamericanos y el funcionalismo europeo de las cofradías. De ahí que tuviera buena acogida la organización de las fiestas parroquiales con abundancia de comidas, música y bebidas. Otro tanto ocurre con los mayordomos de las los santos -y en este caso de las virgencitas - que financian las fiestas. Por supuesto que muchos obispos de entonces y hasta el presente no comparten el festejo popular con excesos de bebida y 
comida. Dolores Aramoni (1996) cita un decreto del obispo Marcos Bravo de la Serna en 1682, dirigido a los cofrades del barrio de Santo Domingo, en Tuxtla Gutiérrez:

Las fiestas que por cuenta de dicho calpul se celebran en la iglesia parroquial, de aquí adelante se celebren en la ermita del calpul, procurando en ella la mayor devoción que es el festivo holocausto que deleita a Dios nuestro señor, y no gasten los bienes eclesiásticos de dicho calpul en vana superfluidad de regocijos, ni en profanos festejos de comidas (Aramoni, 1996:15, en AHD 1682-1845, F. 3v.).

Continúa con otros mandatos que parecieran muy recientes, o que no hubieran cambios después de más de trescientos años, al mencionar que los obispos ordenan hacer una sacristía para guardar todos los ornamentos de los santos para que éstos "no anduvieran de casa en casa", ya que la preocupación básica era que la devoción de la feligresía "se entibiara" al ser manipulados por los albaceas y mayordomos. Además, se argumentó la necesidad de nombrar cada año al mayordomo y sacristán, elegidos con la presencia de los vecinos del calpul, seguramente para evitar liderazgos indígenas. Aún así, prácticamete durante toda la etapa colonial las estancias estuvieron administradas por indígenas, hasta los primeros años del siglo XIX:

En 1809 los zoques de Tuxtla fueron despojados por su cura, tanto de la estancia de Santo Domingo como de la de Copoya -esta última era de ganado vacuno y de ella era de donde salían las reses, para las celebraciones de las otras cofradías-. Los justicias del pueblo pidieron en un escrito dirigido al obispo Ambrosio Llano que se las devolvieran, con el fin de poder vender algún ganado y así costear el arreglo del techo de la iglesia parroquial, que se encontraba lleno de goteras (Aramoni, 1996:18).

La memoria colectiva del pueblo de Copoya reconstruye este hecho y lo relaciona con su propia iglesia. Además, dicen que tomaron la decisión de bajar a las virgencitas a Tuxtla con el fin de recoger las limosnas que ayudarían a reparar el techo de la iglesia, pues señalan que anteriormente era de paja y querían ponerle tejas de barro. Don José (CO69) dice:

Yo recuerdo más claro en el 1944, que ya modernizaron, remodelaron pues el templo, ya se hizo de techo de teja con adobe [...] ya estaba la fiesta [...] según mi abuelito pue, en la libretita esa que dejó, anotó el primer presidente de festejo, de parte de las imágenes de aquí de Copoya, fue el 1901 el primer presidente de festejos fue el señor Valentín Velásquez [...] dicen mi abuelito que por hay fue empezando ya la bajaba de la virgen a Tuxtla ¿Cuál fue la razón? porque aquí en Copoya carecía la gente de Sacerdote, y que ni en Tuxtla porque venia de San Cristóbal, en San Cristóbal estaba la Diócesis [...] por eso venía allá el sacerdote, aparte de eso venían misioneros (trabajo de campo, 2005). 
Durante la aplicación de la Ley Lerdo de 1856, junto con la liberación de los bienes de manos muertas, las compañías deslindadotas arrasaron con los territorios indígenas y con sus bienes comunales y cofradías. A pesar de ese inmenso despojo, las cofradías lograron sobrevivir "gracias más al empeño de los indios que al cuidado de los curas" (Aramoni, 1996:22), quienes fueron quedando al margen de la organización y manejo de los bienes y recursos.

Así se organizó desde entonces las fiestas patronales de las tres virgencitas de Copoya, quienes cuentan con un centenar de "priostes" o principales y más de trecientos socios, además de mayordomos y albaceas, los cuales han recibido en sus casas a las imágenes sagradas. La tradición se construyó de tal manera que todo el municipio de Tuxtla Gutiérrez participa durante la bajada de las vírgenes a la ciudad, así como durante las subidas a Copoya, dos veces por año, sin la participación de los sacerdotes en la organización de las fiestas, pues sólo se les ocupaba para los bautizos, casamientos, primera comunión y fiestas de quince años, o para las misas de los difuntos.

Siendo una comunidad con 420 ejidatarios básicos, que integra a las dos poblaciones de Copoya y El Jobo, pues el ejido abarca a ambas, su población se acerca a los 8, 000 habitantes $-4,500$ en Copoya y 3,500 en el Jobo-. Además de avecindados y pobladores provenientes de diferentes partes del país.

La economía local era de subsistencia, y los varones solían buscar trabajo temporal en la industria de la construcción cuando requerían de dinero. Pero en cuanto se vinieron abajo los precios de los productos agropecuarios y han quedado canceladas las oportunidades de vivir de la agricultura, han tenido que depender cada vez más del empleo que consiguen en Tuxtla. De tal forma que los hombres salen a trabajar como peones, albañiles, fontaneros, carpinteros o pintores; y las mujeres se emplean como trabajadoras domésticas o comercializan tostadas, flores y algunas verduras en el mercado tuxtleco.

Por su parte la vida religiosa, organizadora de las actividades económicas en la agricultura de subsistencia y las festividades de la comunidad, transcurría sin mayores cambios. A 
mediados de los años ochenta del siglo pasado empezaron a comprar tierras en Copoya algunos tuxtlecos que descubrieron el encanto del único pueblecito zoque colindante con la capital chiapaneca. Luego, conforme se encarecían los predios en Tuxtla, y con los cambios en las leyes agrarias en 1992 respecto a las reformas del artículo 27 Constitucional, que permitió la venta de terrenos ejidales, se fue abriendo el mercado para la compra de las parcelas campesinas, ahora ya lotificadas e incrementado su precio. Muchos ejidatarios vieron venir la fortuna que jamás se hubieran imaginado: de 5 o 10 mil pesos que estimaban el precio por hectárea pasaron a pedir primero 100 mil y luego 200 mil pesos, hasta llegar a solicitar medio millón de pesos por hectárea, o de plano, vieron que era mejor vender la tierra por lotes para multiplicar sus ganancias.

Otro fenómeno interesante fue la construcción de la red de agua potable, que ha venido a complementar la demanda de los "fuereños" en la localidad, pues la anterior red es local y administrada por la asamblea ejidal. También la construcción del drenaje, la ampliación de calles y el alumbrado público, la remodelación del parque central, la introducción del teléfono y el incremento del transporte colectivo han sido factores que vinculan más a Copoya con Tuxtla Gutiérrez.

Conforme la comunidad crece y se desarrolla también se incrementaron las peregrinaciones de las virgencitas de Copoya, las cuales se vieron fortalecidas en las fiestas navideñas con la peregrinación de los guadalupanos el 12 de diciembre, además de sus tradicionales "bajadas" a Tuxtla. Sólo en la "subida" de las vírgenes en agosto de 2003 se realizó una multitudinaria concentración en la colonia del Jobo, a un costado de Copoya, donde se presentaron decenas de miles de feligreses, cinco conjuntos musicales, marimbas, juego de fut-bol, enrames y somés de todas partes de Tuxtla, El Jobo, Copoya, Suchiapa y Chiapa de Corzo. La fiesta tardó una semana y se consumieron dos toros, gigantescos peroles de chanfaina, varias ollas de mole con aves de corral, infinidad de cerveza y grandes ollas de pozol.

Hasta 1964 el obispo de San Cristóbal tenía bajo su control formal la feligresía de Tuxtla Gutiérrez. De ese año a la fecha han habido cuatro obispos en la nueva diócesis de Tuxtla: 
1) José Trinidad Sepúlveda, 2) Felipe Aguirre Franco, 3) José Luis Chaves Botello y 4) Rogelio Cabrera, recién llegado en noviembre de 2004.

Es durante el obispado de Chaves Botello, a finales del año 2003, que fue nombrado un sacerdote católico para atender las iglesias de Copoya y El Jobo, el padre José Severo Castellanos Valenzuela. Por su parte, la comunidad de Copoya no había aceptado el dominio de la iglesia, pero el avance de grupos protestantes en la comunidad llevó a los católicos tradicionales a aceptar la presencia del primer sacerdote en su iglesia.

Con el nombramiento del sacerdote y con la aceptación de algunas familias para realizar retiros espirituales convocados por la iglesia -que el padre Severo denomina pomposamente "Movimiento de Encuentro con Dios" (para niños) y "Jornadas de Vida Cristiana" (para jóvenes y adultos)—, se ha dividido la población entre "encuentristas" y "tradicionalistas", y ha iniciado la disputa por la posesión de las virgencitas de Copoya. En marzo de 2004 se produce el primer enfrentamiento, y en abril la violencia se apodera de ambos sectores, al grado de llegar a un intento de linchamiento de los "tradicionalistas" por parte de los "encuentristas".

Actualmente los "encuentristas" afirman que las cosas están en calma, que todo ya pasó y que "los tradicionalistas de Tuxtla" tuvieron que aceptar la devolución de las imágenes para que estuvieran en la Iglesia de Copoya, y que no bajarían más con los borrachos y abusivos de los mayordomos tradicionales, pero la feligresía ha disminuido notablemente y las fiestas se realizan sin el lucimiento con que se unía la pequeña comunidad zoque de Copoya a la gran capital Tuxtleca. Esto no quiere decir que ambas organizaciones sigan creciendo e incrementando su oferta religiosa, ya que al ser retenidas las virgencitas en Copoya, los tradicionalistas de Tuxtla mandaron hacer otra réplica para seguir la tradición, y si dependían de la Iglesia de San Marcos anteriormente, ahora pertenecen a San Pascualito. Don Ricardo (TX70) nos relata:

Llegó la virgen que fue a Copoya, según sé que le quisieron pegar al albacea, una señora, porque dice que cómo esa paga lo está agarrando el albacea ¿no? Nunca se acostumbra a privar o agarrar un quinto del albacea. Nunca acostumbra llevar una paga para su casa, al 
contrario, viene y le pone dos o tres pesos a la alcancía [...] ¿por qué está la Iglesia?, pues la Iglesia pue' ya ve Usted como está la Iglesia, ya lo hicimos, lo hicimos [de la cooperación] Este señor obispo lo ha querido cambiar ¿no?, porque la virgencita siempre llegaba a la Iglesia de San Marcos ¿no?, bendecían y todo. Ahora ya no, ahora pertenecen a San Pascualito, es decir, nosotros [las] llevamos a San Pascualito (Trabajo de campo, 2005).

Sin embargo, el expediente del conflicto religioso ha quedado abierto y la presencia de un ambiente enrarecido se deja entrever en las dos posiciones enfrentadas. La pregunta obligada sigue siendo ¿podrán borrarse décadas de fiestas religiosas en que las virgencitas subían a Copoya y bajaban a Tuxtla Gutiérrez?.

Al iniciar el 2004 ya se veía venir los conflictos, pues el comentario general era en torno a la iglesia y las virgencitas. Los temas recurrentes eran "hay que quitarle a los tuxtlecos nuestras virgencitas, pues ellos las pasean para pedir limosnas y quedarse con el dinero", o bien "no es correcto que se emborrachen y hasta bailen con las virgencitas, ellas merecen respeto y deben estar en su iglesia”.

Pero estas aluciones tienen como antecedente que el Obispo mandara llamar a los albaceas, mayordomos y presidente de la junta de festejos, les preguntara cuándo bajaba la virgen y les impusiera a los tradicionalistas que no bajaran a las virgencitas el 30 de enero, sino el 3 de febrero, argumentando que la virgen de Candelaria debería pasar el día de su festejo -2 de febrero- en su Templo. Don arnulfo (80CO) lo refiere así:

-Miren, dice, de aquí un año ya no va bajar el 30 de enero. Vean, dice, ahora ya no va a ser así, dice el obispo, hagamos esto: va a bajar el 3 de febrero, que lo pase en su templo [el 2 de febrero], porque ustedes saben que todos tenemos una mamacita [...] el día de su cumpleaños que es el 10 de mayo, cuan más celebra su mamacita, y visitan, y así debe de ser en Copoya [...] Entonces, la virgen, el día de su cumpleaños, que lo celebren allá [...], ya el día 3 lo traen como acostumbran. Eso no les gustó, No, dice. No está bien así. -¿A quién no le gustó?

-A los priostes y a don Paulino también, y el Jorge, y No, dicen [...] No padre, ya está todo en calendario, bueno este año ya no se puede, pero ahora en abril que va a subir, vamos a arreglarlo esto, que quede ya listo el año que viene va a bajar el 3 de febrero, para que el día de su cumpleaños allá lo celebren, la virgencita, porque así debe ser, dice, no es posible que pase en los particulares, no, no está bien eso, dice, debe estar en su templo. Es la reyna del pueblo pues, ¿por qué va estar en otro lado, y su red de la familia allá esperando los hijos? 
[es decir, su feligresía] No está bien, dijo, ese nomás le dijo, por eso cuando subió la virgencita ya el 28 de marzo pue' [empezó el pleito] (trabajo de campo, 2005).

Por su parte, los integrantes de la mayordomía zoque no se han quedado callados, por la radio y los diarios locales han expresado su inconformidad, exigen respeto a sus tradiciones y dan a conocer un atentado más a su patrimonio cultural. Argumentan que ha sido vulnerada su cultura cuando la diócesis de Tuxtla Gutiérrez "trata de que se abandone la usanza regional dentro del festejo de las Vírgenes de Copoya. Incluso, dijeron, ya comienza esto a provocar conflictos entre las mismas familias" (Cuarto Poder, 27 de marzo de 2004).

En ese mismo diario se afirma que ante la opinión pública los zoques dieron a conocer un oficio a los representantes de la Diócesis de Tuxtla Gutiérrez, elaborado el pasado 5 de enero, en el que se exige una nueva forma de realizar el festejo. El documento manifiesta que sólo después de una evaluación de la Iglesia tuxtleca, se realizarán los festejos del 2005. Ante ello, Roque López Consospó, integrante de la mayordomía, dijo que esto no será permitido dado el desconocimiento que tienen respecto a su cultura y raíz étnica. Además, rechazó la propuesta de que sea el padre Oscar Juárez quien coordine la comisión de festejos que por décadas ha estado a cargo de ellos (Cuarto Poder, 27 de marzo).

Para esas fechas el ambiente ya estaba muy enrarecido y la policía municipal incrementó su vigilancia, la noticia oficial no se hizo esperar:

Niega arzobispo Chávez Botello problemas con zoques. El arzobispo de Antequera Oaxaca, José Luis Chávez Botello, rechazó que se pretenda causar enfrentamientos entre los pobladores zoques de Copoya, al contrario, el fin es fortalecer sus tradiciones (Tabasco HOY/Notimex, 27 de abril de 2004).

Sin embargo, pese a esta declaración, los mayordomos de las fiestas tradicionales de las virgencitas de Copoya, o también llamadas "Las Copoyitas", se encuentran muy inconformes, ya que afirman que antes de la llegada del padre Severo como párroco de Copoya las cosas marchaban bien. Esta posición se observa en la prensa local, según la cual:

El Párroco de Copoya de apellido Severo, resultó ser un destructor de las tradiciones indígenas, en el municipio de Ixtapa comenzó [....] en el municipio de Suchiapa realizó lo mismo, dividió a la gente, destruyó parte de la cultura que los chiapa o mankemes habían 
guardado por cientos de años, este cura además se robó las campanas de la Iglesia y quiso terminar con la cofradía tradicional, después de haber dejado a Suchiapa toda en conflicto, ahora el señor se va contra la maordomía zoque de Tuxtla (AIZ, 1-IMC, ChiapasIndependent, 16 de mayo de 2004).

Por su parte el arzobispo José Luis Chávez Botello ha insistido que "algunas personas que se identifican como mayordomos y socios" de las virgencitas del Rosario, Candelaria y Santa Teresa, que pertenecen a la parroquia de Candelaria, llevaron a los "santos" fuera del templo, a casas particulares. Por ello -insiste el arzobispo- "la diócesis no puede enfrentarse pero sí propone 'sanear' las fiestas patronales y terminar con el abuso en el consumo del alcohol". En suma, se trata de regresar las imágenes al templo.

Lo curioso es que desde principios del siglo pasado se ha venido realizando la tradicional "bajada" de las virgencitas de la meseta de Copoya a Tuxtla Gutiérrez, haciendo un recorrido 6 kilómetros, descendiendo los 80 metros de altura de la meseta al valle de Tuxtla. Sólo hasta principios del 2003, cuando se nombra al cura José Severo Castellanos Valenzuela como párroco de Copoya y la colonia adjunta El Jobo, y como operador de los cambios al sacerdote Oscar Campos, dan inicio algunos descubrimientos y anomalías de la religiosidad popular, a decir de los especialistas de la Diócesis, según el Diario de Chiapas, del 17/10/2004:

- Los rituales para festejar a las tres virgencitas del pueblo de Copoya son más paganos que religiosos, lo cual no cumple con una ceremonia de adoración de las virgencitas.

- La celebración de "las copoyitas" - como también se nombra al conjunto de vírgenes - se hace en casas particulares, habiendo infinidad de templos católicos en el sur de la ciudad por donde se podría celebrar a las imágenes.

- Durante la celebración se consumía gran cantidad de alcohol y mucha música, lo cual tampoco cumple con una ceremonia religiosa.

Lo que se olvida es que "Las copoyitas" son la principal tradición religiosa de Tuxtla, que forma parte de la historia de Chiapas, que es el único pueblo cercano a la ciudad que ha conservado su identidad colectiva en torno a su estructura económico—religiosa, que logra 
construir una lógica de la unidad entre sus pobladores sin atender a las diferencias económica, sociales y hasta políticas, y que, por tanto, aparece tanto en los referente cotidianos como en la narrativa chiapaneca y en diversos estudios sobre la cultura zoque. ${ }^{8}$ Entre lo poco que queda del acervo artístico de la región, tenemos

La música en el alma: La población indígena de nuestro estado se sirvió de bailes y cantos llenos de poesía para alabar a sus dioses y honrar sus creencias. Así fue haciendo una música que los mayores heredaron a los jóvenes, enseñándolos en el arte de crear sugerentes murmullos o ruidosa algarabía [...] En efecto, solo restos musicales se conservan del pasado. Nos queda, por ejemplo, la música de los zoques de la región Central (Tuxtla, Copoya, Suchiapa), donde hasta la fecha los instrumentos precolombinos acompañan las danzas tradicionales. (C:I2004lDICIEMBREIChiapas_com_mx - Ventana a la Frontera Sur.htm).

Sin embargo, con el desempleo agropecuario, la imposibilidad de sobrevivir de la producción en el campo y el incremento de la emigración, se ha creado la dependencia alimentaria, predominantemente por la vía del salario. Junto con ello se ha venido desintegrando la estructura organizativa rural, que privilegia las fiestas tradicionales y religiosas ligadas a las actividades productivas. Con el avance de la música moderna también va desapareciendo la marimba, el tambor y la flauta, y las generaciones jóvenes prefieren el teclado y la música de banda, y otro tanto sucede con el vestido y los patrones alimenticios.

En este contexto, la disputa por la virgencitas es la expresión de fuertes desencuentros entre la crisis del catolicismo y el avance de la urbanización, por un lado; por otro, nos encontramos con poco más de un centenar de mayordomos que se aferran a sus tradiciones y encuentran en la religiosidad popular una válvula de escape ante los problemas socioeconómicos de la fase de la globalización que nos ha tocado vivir. Una fase donde se va perdiendo el patrimonio cultural estructurado en el eje de la milpa, la vida basada en una alimentación con maíz y frijol, con yerbas y verduras, con animales de patio y vestimenta de manta y tejidos tradicioales. Desaparecen las viviendas con muros de barro, adobe, techos de teja y pisos de tierra apisonada, con espacios amplios, huertos en el patio trasero y grandes áreas para los niños y adultos. En suma, es la pérdida de la comunidad agraria

\footnotetext{
${ }^{8}$ En la obra de Dolores Aramoni Los refugios de Io sagrado, CONACULTA, 1992, el titulo es muy sugerente para continuar la trayectoria presente del fenómeno religioso en Copoya.
} 
que, al verse rota, se aferra al eje que estructuraba su economía y su cultura en la organización de la convivencia social: Las virgencitas de Copoya.

El 31 de enero de 2005 se reunieron en la "Quinta Mechita" -casona particular que ofreció su dueña, en la entrada de Copoya - los desplazados albaceas, mayordomos, priostes y socios (principales que organizan las fiestas), con sus tres nuevas vírgenes. Realizaron todo el ritual de bañar, lavar las ropas, vestir y hacer los grandes bultos con las virgencitas, forrados con petates nuevos y cintas tejidas a mano, propias para cargarlas durante tramos extenuantes. Con ellas bajaron a Tuxtla, atravesaron la ciudad y fueron a cumplir las promesas de visitar a sus solicitantes en las viejas listas, que habían quedado pendientes con las anteriores administraciones de las virgencitas antiguas.

El 13 de marzo nuevamente se vió ascender a estas virgencitas, acompañadas de cientos de peregrinos que suspendieron el tráfico por más de dos horas en el trayecto de Tuxtla a Copoya. A la vez, salían de sus "Encuentros con Cristo" los seguidores del padre Severo y, aunque el ambiente era festivo, se observaban claramente dos posiciones radicalmente opuestas, lo que nos hizo pensar en lo importnte de la tolerancia, de los límites, de los territorios y del respeto a las fronteras. En efecto, cada fiesta en su lugar: los seguidores del padre Severo se movían en el centro del poblado, mientras que los tradicionalistas mayordomos zoques lo hacían en las afueras de la comunidad, rodeados de mayor concurrencia, de futbolistas y peregrinos, y resguardados por sus nuevas vírgenes, pero con sus mismos y anteriores compromisos.

\section{REFLEXIÓN FINAL}

Considero que tal disputa se centra en tres aspectos básicos:

\section{1) El control económico}

La Iglesia católica, representada en la figura del padre Severo, ha metido en cintura a la parroquia de Copoya, mediante la recuperación de las vírgenes. Aseguran que los mayordomos controlaban todas las limosnas que la feligresía hacía a las virgencitas, y que consistía en joyas y dinero, lo cual les traía abundantes ganancias. Además -asegura la 
Iglesia - realizaban actos paganos que desprestigiaba a las imágenes y servían para dar rienda a sus vicios, bailes y festividades, con lo que nuevamente aumentaban las ganancias de los responsables de las vírgenes, organizados por la Junta de Festejos.

Por su parte, los mayordomos afirman que el padre Severo está cobrando por sus servicios, desde \$ 100.00 hasta $\$ 300.00$ por bautizos, casamientos, misas y otros servicios. Incluso cobra para dar los santos óleos a las personas moribundas, y si no se le paga él no acude al servicio religioso. Tambien afirman que en plena misa el cura pide limosna porque "ya se acerca el pago de la letra del coche -afirma bromenado-_". La acusación mutua en torno a los dineros de la Iglesia y de la virgencitas ocupa el primer lugar de la disputa.

\section{2) El poder político}

La iglesia está interesada en la feligresía de Copoya y El Jobo, pues ante el avance de los protestantes y la autonomía de los rituales tradicionales de las virgencitas de Copoya, se le hacía aparecer como incapaz de "meter en cintura" esas fiestas "paganas". Además, el debilitamiento del poder eclesiástico requería de un cambio radical, de un golpe de timón, que fuera notorio y advirtiera a la población de la capital tuxtleca y de toda la entidad que la iglesia aún tiene autoridad.

Por su parte, los tradicionalistas argumentan "nosotros somos la iglesia, el pueblo, y con los obispos o sin ellos seguiremos festejando a nuestras virgencitas”. En clara afrenta a las decisiones del obispo, han mandado hacer una réplica de sus virgencitas y las reciben en la "Quinta Mechita", a la entrada de Copoya, donde acude mayoritariamente gente de Tuxtla para iniciar el descenso de las vírgenes el 31 de enero del 2005. Se constituyen como un grupo mayoritario y -revitalizados- continúan con la tradición de unir Copoya con la ciudad capital de Chiapas.

\section{3) El prestigio social}

Para la Iglesia Católica, haber recuperado las virgencitas de Copoya para dejarlas en el templo, es una muestra de su presencia y de su prestigio -no sólo en las dos pequeñas comunidades, sino en Tuxtla y Chiapas-. Su endurecimiento responde más a sus 
profundas preocupaciones del descenso de credibilidad ante los avances del protestantismo, que enfrentarse con los cientos de "priostes" incómodos y molestos.

Los "priostes" -y los miles de peregrinos que les acompañan - se propusieron en enero del 2005, bajar por primera vez con sus nuevas virgencitas de Copoya $\mathrm{y}$, en vez de recorrer con ellas sólo el área sur de la ciudad, atravesaron toda la mancha urbana y entregaron las vírgenes a quienes solicitaron su presencia en el lado opuesto a Copoya. Con ello se hace una gran demostración de fuerza, de organización y de presencia y prestigio social. El ambiente festivo atrajo la ateción de propios y extraños. El comentario general era: "las copoyitas seguirán con la costumbre, lo quiera o no el obispo de Tuxtla" y "¡velo miralo vé, que burrosi ¿a quién se le ocurre terminar con esta tradición?”.

\section{LITERATURA CITADA}

Aramoni Calderón, Dolores. 1992. Los refugios de lo sagrado. Religiosidad, conflicto y resistencia entre los zoques de Chiapas. Consejo Nacional para la Cultura y las Artes.

Delgadillo, Raquel, 1997. Población y estructura urbana en las colonias periféricas de

Tuxtla Gutiérrez. En Aspectos Urbanos y Arquitectónicos de Tuxtla Gutiérrez. Cuadernos de Arquitectura y Urbanismo No. 3. Facultad de Arquitectura. Universidad Autónoma de Chiapas. México.

Escobar, Héctor. 1997. La Urbanización periférica de Tuxtla Gutiérrez. En Aspectos Urbanos y Arquitectónicos de Tuxtla Gutiérrez. Cuadernos de Arquitectura y Urbanismo No. 3. Facultad de Arquitectura, Universidad Autónoma de Chiapas. México.

Fábregas, P. A. 1985. La formación histórica de la frontera sur. CIESAS-Sureste y Cuadernos de la Casa Chata núm. 124, México.

Favre, Henri, 1973. Cambio y continuidad entre los mayas de México. Contribución al estudio de la situación colonial en América Latina. México, INI.

García de León, Antonio. 1985. Resistencia y Utopía. Memorial de agravios y crónica de revueltas y profecías acaecidas en la provincia de Chiapas durante los últimos quinientos años de su historia. Ediciones Era, México. 
Malo, Clodoveo. 1997. La Dinámica de crecimiento demográfico de la ciudad de Tuxtla Gutiérrez. En Aspectos Urbanos y Arquitectónicos de Tuxtla Gutiérrez, Cuadernos de Arquitectura y Urbanismo No. 3, Facultad de Arquitectura, Universidad Autónoma de Chiapas.

Mérida Mancilla Arturo. 2000. Cien años de evolución urbana en Tuxtla Gutiérrez,

Chiapas. Universidad Autónoma de Chiapas y H. Ayuntamiento Constitucional de Tuxtla Gutiérrez, Chiapas, México.

Morales Avendaño, Juan María, 1980. Pequeña monografía del municipio de Tuxtla Gutiérrez, Chiapas. Mimeo, Rincones de Chiapas, Colección Chiapas, Centro de Investigaciones Ecológicas del Sureste, CIES.

Noguez, Carlos. 1997. Cambios territoriales y transformaciones socioculturales en Tuxtla Gutiérrez: 1940-1995. En Aspectos Urbanos y Arquitectónicos de Tuxtla Gutiérrez, Cuadernos de Arquitectura y Urbanismo No. 3, Facultad de Arquitectura, Universidad Autónoma de Chiapas, México.

Rivera Farfán, Carolina, Miguel Lisbona y María del Carmen García. 2004. Chiapas

Religioso. Dirección de Divulgación de la Secretaría de Educación, Gobierno de Chiapas, Tuxtla Gutiérrez, Chiapas, México.

Tovar González, María Elena. 1988. Tuxtla y su feria de San Marcos. Gobierno del Estado e Instituto Chiapaneco de Cultura.

Thompson, Roberto y María de L. Poo. 1985. Cronología histórica de Chiapas (15161540) San Cristóbal de Las Casas, Chiapas. Centro de Investigaciones Ecológicas del Sureste.

Villasana Benítez, Susana. 1995. Cambios territoriales del área cultural zoque. Un seguimiento histórico. En Anuario IEI $V$, ed. Instituto de Estudios Indígenas, Universidad Autónoma de Chiapas, México.

Villa Rojas, Velasco T., Báez-Jorge, Córdova, D. Thomas. 1975. Los zoques de Chiapas. Colección SEP--INI núm. 39, Instituto Nacional Indigenista y Secretaría de Educación Pública, México. 


\section{Jorge Luis Cruz Burguete}

Doctor en Ciencia Social con especialidad en Sociología por El Colegio de México, México. Maestría en Sociología Para el Desarrollo Regional por el IISUABJO, Ciudad de Oaxaca. Licenciado en Economía por la Universidad Autónoma de Chiapas, San Cristóbal de Las Casas, Chiapas. Actualmente Profesor Investigador Titular, Profesor del Postrado de El Colegio de la Frontera Sur (ECOSUR), Chiapas. Miembro del Sistema Nacional de Investigadores e Investigador Honorífico del Sistema Estatal de Investigadores de Chiapas. Correo electrónico: jcruz@ecosur.mx

\section{Patricia Elizabeth Almazán Esquivel}

Licenciatura en pedagogía por la Facultad de Humanidades de la Universidad Autónoma de Chiapas y Maestra en Ciencias de la Educación por el Colegio de la Frontera Sur, Chiapas. 